\title{
Scaling apparent distance in natural indoor settings'
}

\section{MARTHA TEGHTSOONIAN and ROBERT TEGHTSOONIAN, Smith College, Northampton, Mass. 01060}

Apparent distance was scaled by the method of magnitude estimation in two indoor viewing situations. The average exponent of a power function relating judged to real distance was 1.2; the exponent was not affected by a doubling of the distance range. Individual judgments were well described by power functions. The results are consistent with those of other studies in showing that apparent distance is an accelerating function of physical distance in indoor settings.

The variables upon which depth discriminations depend have been identified and their relative contributions extensively studied, e.g., Graham (1965). However, it does not follow, from the ability of an $\mathrm{O}$ to discriminate accurately among distances, that the relation between physically measured distances and the appearance of distance to the $O$ is one of identity, or even that it is linear. Knowledge of the conditions that make depth discrimination possible does not provide a scale of apparent depth or distance. Several studies have undertaken to determine the form of such a scale and to provide a precise description for it. Gilinsky (1951) used both subjective bisection and a method in which the $O$ determined the marking-off of successive equal-appearing intervals. Her results suggested that apparent distance was a decelerating function of physical distance, a finding which was later confirmed by Harway (1963), using the method of successive equal-appearing intervals, but with substantially larger samples of Os. Data suggesting a different relation between apparent and physical distance have been reported by E. J. Gibson and her associates. Purdy \& Gibson (1955) discovered that Os could bisect and trisect distances rather accurately, and Gibson \& Bergman (1954) and Gibson, Bergman, \& Purdy (1955) found that Os could estimate physical distance quite accurately; they concluded that the psychological scale of distance was linear with physical distance. There is also some evidence for a third alternative-that when Os are asked to judge target distances, the judgments are positively accelerated functions of physical distance. Künnapas (1960) reported a series of experiments in which ratio estimations were made of pairs of indoor distances: apparent distance was a power function of physical distance with an exponent ranging from 1.2 to 1.5. Luria, Kinney, \& Weissman (1967) had Os make distance judgments relative to a $2-\mathrm{ft}$ standard distance; those judgments were power functions of target distance with exponents of 1.2 to 1.3. (Luria, Kinney, and Weissman did not fit power functions to their data. Median distance estimates were read from their Figs. 1 and 2, and least-squares fits found for $\log$ distance estimates as a function of log target distances.)

Some experimental support, then, is available for each of three possible relations between apparent and physical distance-that it is negatively accelerated, linear, or positively accelerated. At least some of the disagreement may be due to the diversity of scaling techniques that have been used, and to the variations in many aspects of the test conditions-range of distance, availability of cues to distance, the set produced by instructions, and the location of the test, indoors or outdoors. It seemed desirable to explore the effect of some of these factors by scaling apparent distance in a variety of situations with a standard technique. We chose a version of magnitude estimation currently in wide use, which entails the assignment of numbers by the $\mathrm{O}$ to match some aspect of the stimulus, but designates no standard and assigns no modulus.

One generalization suggested by previous work is that while apparent distance has often been reported to be a linear or decelerating function of physical distance, the exceptions to this rule have involved indoor viewing situations (Künnapas, 1960; Luria, Kinney, \& Weissman, 1967). Accordingly, the first studies initiated explored apparent distance judgments in indoor settings which were familiar to $O$ s and which incorporated many natural cues to distance. In the first experiment, Os judged the apparent distance of targets located from 5 to $45 \mathrm{ft}$ away in a large classroom. The second experiment was conducted in a corridor with targets at 5 to $80 \mathrm{ft}$ away.

\section{EXPERIMENT 1 Subjects}

There were $16 \mathrm{Ss}$, women undergraduates, who volunteered and were paid for their time.

\section{Materials}

There were five target distances- 5,15 , 25,35 , and $45 \mathrm{ft}$. These distances were marked by irregular polygons, cut from black matte cardboard; there were 10 such polygons, each different in shape and area, which ranged from 5 to $400 \mathrm{sq}$ in. The markers were presented by attaching them to a stand; the stand, with marker attached, was placed on a table top. The marker was in S's frontal-parallel plane and at eye level when $S$ was seated.

The room used was a large classroom, about $50 \mathrm{ft}$ long. $S$ sat at one end of the room and looked out at five rows of tables and chairs, perpendicular to her line of sight, in the central portion of the room; there were also single tables, one close to her and one at the very back of the room. Some of these tables were moved out of line and used as convenient locations for the marker at the target distances. Otherwise the room was not changed; the aim was to have a normal viewing situation, in which various cues to distance would operate as they usually do. Procedure

The instructions told S she was to see a series of distances, which would be marked by irregularly shaped figures of different shapes and sizes; S's task was to assign numbers to represent how far away the markers looked to her. S was encouraged to use any numbers that seemed appropriate, as long as they were proportional to the apparent distance of the markers.

The target distances were presented one at a time: $S$ turned away while $E$ placed a marker, then at a signal turned back and

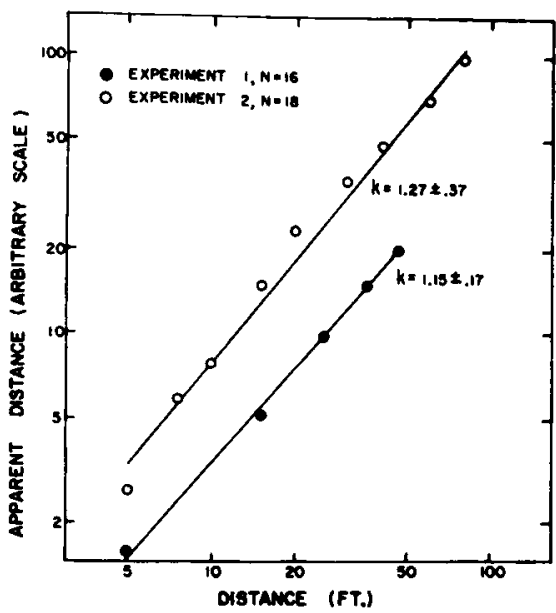

Fig. 1. Geometric means of magnitude estimations of apparent distance in two indoor settings; apparent and physical distance are scaled logarithmically. Each S made two judgments at each distance. The values for Experiment 2 are those obtained; the values for Experiment 1 have been divided by a constant factor (about 2.5 ) so that they could be displayed conveniently. The slopes represent least-squares fits; the standard errors were calculated from variance components derived from analyses of variance. 


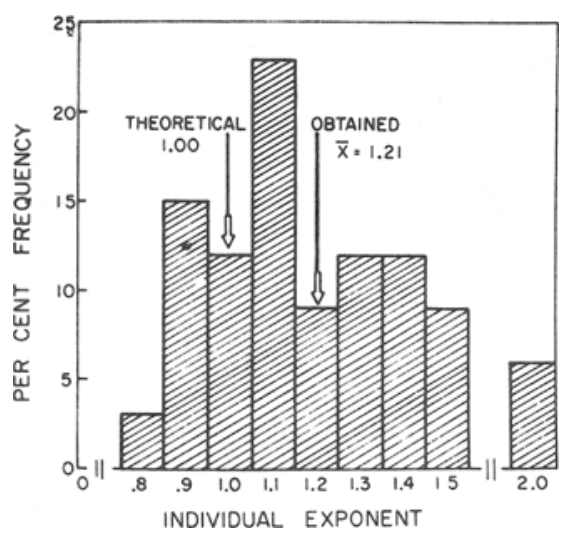

Fig. 2. Individual distance exponents. The per cent frequency distribution of slopes of least-squares fits to individual log magnitude estimations of apparent distance combines data from Experiments $1(N=16)$ and $2(N=18)$. The mean of the combined distributions is indicated, as is the value, 1.0, which represents judgments linear with distance.

made her judgment. Each target distance was presented twice. The combinations of distance and marker were determined randomly for each $\mathrm{S}$, as was the order of their presentation.

\section{Results}

For each $S$, the two judgments for each stimulus were logarithmically transformed and the mean taken; these individual mean log magnitude estimations constituted the scores, on which an analysis of variance was performed. The effect due to distance was of course significant $(\mathrm{p}<.01)$. The mean scores (log geometric means) were plotted against log physical distance and are shown by the filled circles in Fig. 1. The best-fitting straight line was determined by the method of least squares; its slope, which is the exponent of a power function, was 1.15. A $t$ test showed the exponent was significantly different from a theoretical value of 1.00 $(\mathrm{t}=2.74, \quad \mathrm{df}=15, .02>\mathrm{p}>.01)$. The adequacy of the power function to describe the data was indicated by the finding that $99.6 \%$ of the variance in the mean scores was accounted for by the fitted line; the analysis of variance showed that deviations from linear regression were not significant $(p>.25)$. The analysis of variance showed that the differences among $S s$ in both intercept and slope of individual least-squares fits were significant $(p<.01)$; the slopes-which may be regarded as exponents of individual power functions-ranged from 0.89 to 1.50 , and were characterized by a mean coefficient of determination of .979 .

Another study (Teghtsoonian \& Teghtsoonian, 1966) of size judgments with distance varying obtained, in a final portion

of the procedure, magnitude estimations of apparent distance in the same setting, with the same target distances, as Experiment 1. With $18 \mathrm{Ss}$, the exponent of the power function relating apparent to physical distance was 1.17 . Thus, a replication of the study yielded almost identical results. EXPERIMENT 2

\section{Subjects}

Eighteen women undergraduates served as Ss. Six served as part of a course requirement, while 12 were volunteers.

\section{Materials}

Nine target distances-5, 7.5, 10, 15, 20, $30,40,60$, and $80 \mathrm{ft}$-were used. They were inconspicuously marked (so that $\mathrm{E}$ could identify them) with tape along the side of a long corridor, $99 \mathrm{ft}$ in length and $11.5 \mathrm{ft}$ wide. $S$ sat $5 \mathrm{ft}$ from one end of the corridor, and the target distances ranged in front of her to the $80-\mathrm{ft}$ distance, which was $14 \mathrm{ft}$ from the other end of the corridor. Doors along the corridor and other repeating architectural details provided an abundance of linear-perspective cues; painted walls and linoleum floor provided some textural-gradient cues. The target distances were marked for $\mathrm{S}$ by white cardboard rectangles which sat upright on the floor of the corridor; there were nine markers, ranging in size from $5.5 \times 2.5 \mathrm{in}$. to $27.5 \times 17.5$ in.

\section{Procedure}

The procedure was the same as that in Experiment 1. Each $\mathrm{S}$ made magnitude estimations of the apparent distance of the markers, twice at each of the nine target distances. Markers were paired with distances in a random fashion, and a different random order of presentation was used for each $\mathrm{S}$.

\section{Results}

The treatment of results was the same as for Experiment 1. The analysis of variance showed the effect due to distance was significant $(p<.01)$; the mean linear regression accounted for $99.5 \%$ of the variance, and the deviations from mean linear regression were not significant (.10) $<\mathrm{p}<.25$ ). Unfilled circles in Fig. 1 show the log geometric mean magnitude estimations against log physical distance; the slope of the fitted line is 1.27. A t test indicated that the slope was significantly different from a theoretical value of 1.00 $(t=2.93, d f=17, p<.01)$. The differences among $\mathrm{Ss}$ in both intercept and slope of individual least-squares fits was significant $(p<.01)$. Individual slopes ranged from 0.81 to 2.25 ; the mean coefficient of determination for individual functions was .963 .

The difference between the mean exponents obtained in Experiments 1 and 2 was tested and found to be not significant $(t=1.10, d f=32, p>.10)$. A frequency distribution of all 34 individual exponents is shown in Fig. 2; the mean exponent of the combined distributions is 1.21. The coefficients of determination for all 34 individual power functions had an average value of .971 and a standard deviation of .038 .

\section{DISCUSSION}

Our results confirm those of Künnapas (1960) and of Luria, Kinney, \& Weissman (1967) in giving an exponent greater than 1.0 for indoor viewing. For two stimulus ranges, the mean exponents are 1.15 and 1.27 , both significantly greater than 1.00 , but not different from each other. This agreement was obtained in spite of differences in technique-ratio estimation for Künnapas, magnitude estimation with a standard and modulus for Luria, Kinney, Weissman, and free-modulus magnitude estimation in our experiments.

However, our results do not confirm Künnapas's (1960) in showing a dependence of exponent on range of stimulus values. In his experiments, an increase in exponent was associated with a decrease in ratio of largest to smallest distance, although he did not test the significance of the obtained differences. In our experiments, a twofold increase in the ratio of distances produced no significant change in exponent.

The finding that judged indoor distances may follow a power function of physical distance with an exponent greater than 1.0 is of theoretical as well as empirical interest. It provides a considerable constraint on theories about an 0 's operations on distance cues. For example, in versions of the size-distance invariance hypothesis which involve apparent distance combining with retinal size, the scale of apparent distance must be known to make adequate predictions about apparent size. Sternberg (1966) has shown that a variety of models of the size-distance invariance hypothesis can be developed, and that the nonlinearity of the apparent distance function is important in differentiating among them. In general, this nonlinearity makes it unwise to study any visual phenomenon which may be influenced by apparent distance (e.g., apparent size, apparent speed) at a single arbitrarily selected viewing distance. That commonly used procedure appears to have rested on the assumption that apparent and physical distance are identical; at least for indoor distances, the current weight of evidence argues that they are not.

\section{REFERENCES}

GIBSON, E. J., \& BERGMAN, R. The effect of training on absolu te estimation of distance over the ground. Journal of Experimental Psychology, 1954, 48, 473-482. 
GIBSON, E. J., BERGMAN, R., \& PURDY, J. The effect of prior training, with a scale of distance on absolute and relative judgments of distance over ground. Journal of Experimental Psychology, 1955, 50, 97-105.

GILINSKY, A. S. Perceived size and distance in visual space. Psychological Review, 1951, 58, 460-482.

GRAHAM, C. H. Visual space perception. In C. H Graham (Ed.), Vision and visual perception. New York: Wiley, 1966.

HARWAY, N. I. Judgment of distance in children and adults. Journal of Experimental Psychology, 1963, 65, 385-390.

KÜNNAPAS, T. Scales for subjective distance. Scandinavian Journal of Psychology, 1960, 1 , 187-192.

LURIA, S. M., KINNEY, J. A. S., \& WEISSMAN, S. Distance estimates with "filled" and "unfilled" space. Perceptual \& Motor Skills, $1967,24,1007-1010$.
PURDY, J., \& GIBSON, E. J. Distance judgment by the method of fractionation. Journal of Experimental Psychology, 1955, 50, 374-380.

STERNBERG, S. Four theories of the effect of distance on apparent size. Paper presented at a meeting of the Psychonomic Society, 1966.

TEGHTSOONIAN, M., \& TEGHTSOONIAN, R. Size constancy: Magnitude estimations as functions of stimulus area and distance. Paper presented at a meeting of the Eastern Psychological Association, 1966.

NOTE

1. We thank Sandra Eber, who ran Ss for Experiment 1, and Eleanor Oldach, who ran Ss for Experiment 2 .

\section{Anxiety and volunteering}

JOHN C. BAREFOOT, Dartmouth College, Hanover, N.H.03755

It was suggested that the relationship between anxiety and volunteering might best be studied using an anxiety scale which is not clinically oriented, such as the Activity Preference Questionnaire (APQ). Anxiety levels of introductory psychology students were assessed using the $A P Q$ and the Taylor Manifest Anxiety Scale(TMAS). $A P Q$ scores were significantly related to the tendency to volunteer for psychological experiments. High anxious Ss participated in more experiments than did moderate or low anxious Ss. TMAS scores were not related to experimental participation.

Since psychological research is often based on data obtained from volunteer Ss, the generality of many studies is dependent on the representativeness of volunteer samples. Several studies have investigated the characteristics of volunteers(Bell, 1962; Rosenthal, 1965), but the findings have not always fit into a coherent pattern. Attempts to discover a relationship between anxiety and the tendency to volunteer have yielded particularly confusing results. Scheier (1959), using the IPAT anxiety scale, found that volunteers for a study of anxiety were less anxious than nonvolunteers. Rosen (1951) and Schubert (1964), using the MMPI Pt (psychasthenia) scale, found volunteers to have higher anxiety than nonvolunteers. Martin \& Marcuse (1958) asked students to volunteer for experiments on several topics and compared their Taylor Manifest Anxiety Scale (TMAS) scores with the scores of nonvolunteers. While they found no differences between volunteers and nonvolunteers if the experiments were concerned with learning or sex attitudes, volunteers for a personality experiment were higher in anxiety than nonvolunteers. Heilizer (1960), Himelstein (1956), Howe (1960), and Seigman (1956) report no relationship between TMAS scores and the tendency to volunteer.

As Bell (1962) has suggested, clinically-oriented tests may not be the most relevant measuring instruments for a normal population. Tests which are not based on the self-report of pathological symptoms might therefore be useful in studies of volunteering. Lykken (1957) has devised an anxiety scale, the Activity Preference Questionnaire (APQ), which meets this criterion. The present study was designed to test the relationship between $A P Q$ scores and the tendency to volunteer.

The short form of the APQ consists of 33 forced-choice items, each listing two rather unpleasant activities. The $S$ is asked to choose the activity which he would prefer. One of the alternatives is unpleasant because of its anxiety-arousing nature (e.g., "Being interviewed for a job"), while the other is not anxiety-arousing, but is unpleasant because of its onerous nature (e.g., "Washing the dinner dishes"). Presumably, those people who are most subject to anxiety should choose fewer of the anxiety-arousing alternatives. The APQ has been shown to predict performance on an avoidance task in which learning is facilitated by fear (Lykken, 1957; Schachter \& Latané, 1964), the degree of disturbance of rescue workers at the scene of a disaster (Latane \& Wheeler, 1967), and self-reports of nervousness during a psychological experiment (Barefoot, 1967). In addition, the scale has distinguished sociopathic prisoners from normals (Lykken, 1957; Schachter \& Latané, 1964). Interestingly, Valins (1967) has also shown that those Ss identified by the APQ as low anxious are less likely to keep appointments to participate in an experiment than are highly anxious Ss.

In the present study, the volunteering act was defined so as to be relevant to a wide variety of laboratory experimentation. APQ and TMAS scores of introductory psychology students were compared to the number of experiments in which each student participated during the term.

\section{METHOD}

Data were obtained from three classes of introductory psychology at Dartmouth College, 1967 Fall term, 1968 Spring term, and 1969 Winter term. The tendency to volunteer was defined as the number of experiments in which each student participated during the term. At Dartmouth, introductory psychology students have the opportunity to participate in a variety of experiments, but there is no course requirement that they do so. They can gain some course credit by their participation, however. Most students were freshmen or sophomores, and no females were included in the samples.

Each student's score on the Taylor Manifest Anxiety Scale (Taylor, 1953) was obtained from his responses to the MMPI, which is administered to all entering Dartmouth freshmen. TMAS scores were available for $95 \%$ of the students enrolled in the classes which were studied.

The methods of administering the APQ (Lykken, 1957) differed between the three terms. In the Fall term, 1967, all students were asked to complete the APQ during the regular class period. Scores were obtained for $90.8 \%$ of the students enrolled in the course. In the 1968 and 1969 terms, students did not fill out the scale during the regular class period, but during a "general testing session" for which the students volunteered and received the usual experimental credit. Additional scores were obtained during the 1969 term from students who participated in two unrelated experiments. APQ scores were obtained from $43.7 \%$ of those enrolled in the 1968 term and $57.3 \%$ of those enrolled during the 1969 term.

\section{RESULTS}

The correlation between APQ and TMAS scores (all samples combined) is -.07 , a result which is in line with previous research on these scales (Lykken \& Katzenmeyer, 1968).

Since the opportunities for volunteering varied between terms, the three samples cannot be pooled and they were treated as replications.

TMAS as a Predictor of Volunteering

Students in each sample were divided into high-, moderate-, and low-anxiety categories on the basis of their responses to the TMAS. High-anxious Ss had scores of 21 or greater while low-anxious Ss had scores of 7 or less. These criteria were identified by Taylor (1953) as the 80th and 20th percentiles of 